\title{
Twenty Years of Experience with Intra-operative Pulmonary Artery Stenting
}

Running Head: Intra-operative pulmonary artery stents

Jeffrey D. Zampi, MD ${ }^{1}$, Emefah Loccoh ${ }^{2}$, Aimee K. Armstrong, MD ${ }^{3}$, Sunkyung Yu, MS ${ }^{1}$, Ray Lowery ${ }^{1}$, Albert P. Rocchini, $\mathrm{MD}^{1}$, and Jennifer C. Hirsch-Romano, MD, $\mathrm{MS}^{4}$

${ }^{1}$ University of Michigan Congenital Heart Center, C.S. Mott Children's Hospital, 1540 East Hospital

Drive, floor 11, Ann Arbor, Michigan 48109. Division of Pediatric Cardiology

${ }^{2}$ Ohio State University College of Medicine, 370 West 9th Avenue, Columbus, Ohio 43210.

${ }^{3}$ Nationwide Children's Hospital, 700 Children's Drive, Columbus, Ohio 43205. Division of Pediatric

Cardiology

${ }^{4}$ University of Michigan Congenital Heart Center, C.S. Mott Children's Hospital, 1540 East Hospital Drive, floor 11, Ann Arbor, Michigan 48109. Department of Cardiac Surgery

Keywords: Congenital heart disease, stenting technique, hybrid revascularization (peripheral)

Word Count: 4254

Corresponding Author: Jeffrey Zampi, MD

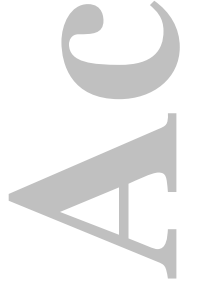

Assistant Professor of Pediatric Cardiology, University of Michigan Congenital

Heart Center, C.S. Mott Children's Hospital Floor 11, Room 715Z

1540 E. Hospital Drive, Ann Arbor, MI 48109-4204

Email: jzampi@med.umich.edu, Phone: 734-936-3813,Fax: 734-936-9470

This is the author manuscript accepted for publication and has undergone full peer review but has not been through the copyediting, typesetting, pagination and proofreading process, which may lead to differences between this version and the Version record. Please cite this article as doi:10.1002/ ccd.27094. 


\begin{abstract}
Objectives: To describe our 20-year experience with intra-operative pulmonary artery stent placement and evaluate long-term patient outcomes, specifically the need and risk factors for re-intervention.

Background: Intra-operative pulmonary artery stent placement is an alternative to surgical patch arterioplasty and percutaneous angioplasty or stent placement to treat branch pulmonary artery (PA) stenosis.
\end{abstract}

Methods: We performed a retrospective review of all intra-operative pulmonary artery stents placed at our institution from 1994-2013. Patient and stent characteristics and outcome data were collected. Risk factors associated with re-intervention were identified using univariate cox regression analysis.

Results: Eighty-one PA stents were placed in 68 patients. The procedural complication rate was 4.4\%. During a median follow-up period of 6 years (interquartile range (IQR) $0.9-12.7$ ), 30 patients (44\%) underwent re-intervention on the stented PA with a median time to first re-intervention of 2.6 years (IQR 0.7-4.4 years). The first re-intervention was surgical in 30\% and catheter-based in $70 \%$. Risk factors for re-intervention included age $<18$ months (Hazard ratio [HR] 2.97, $\mathrm{p}=0.005$ ) and body surface area $<0.47$ $\mathrm{m}^{2}(\mathrm{HR} 3.20, \mathrm{p}=0.003)$ at the time of stent implantation, and the presence of multiple aorto-pulmonary collaterals in patients with tetralogy of Fallot (HR 4.61, $\mathrm{p}=0.003)$.

Conclusions: Intra-operative PA stent implantation is a safe and effective alternative to percutaneous stent implantation and offers several advantages, including the ability to implant adult-size stents in small patients while avoiding injury to peripheral vessels, to position stents to facilitate future percutaneous stent re-dilation, and to access the PAs directly, which eliminates radiation exposure.

Abstract Word Count: 250 


\section{INTRODUCTION}

Branch pulmonary artery (PA) stenosis is a relatively common problem in congenital heart disease.

Percutaneous techniques have reduced the need for surgical pulmonary arterioplasty and are as effective as surgical arterioplasty while avoiding cardiopulmonary bypass (CPB) (1-3). However, many patients

still require operative repair either due to the morphology of the stenosis, inadequate response to

percutaneous techniques, small patient size prohibiting safe or effective percutaneous intervention, or the need for concomitant repair of other surgical defects (1). Re-intervention for recurrent stenosis after surgical pulmonary arterioplasty is required in $48-64 \%$ of patients and has not changed significantly over the last 40 years (2-5). Because of early restenosis, these patients can require multiple surgical or catheterization procedures early in childhood, exposing them to the risks of repeated sternotomy, $\mathrm{CPB}$, and/or radiation, to name a few.

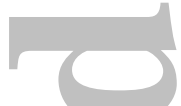

Intra-operative PA stent placement is an alternative approach. This procedure has been shown to be safe with excellent short-term efficacy (6-14). It can allow for implantation of stents that can be dilated to adult size that would be difficult to place percutaneously in small children, while avoiding ionizing radiation exposure from cardiac catheterization procedures. However, longer-term data on the outcomes of intra-operative PA stenting are limited (15).

We sought to describe our experience with intra-operative PA stent placement over the last 20 years and to examine long-term patient outcomes, specifically focusing on the incidence of and risk factors for reintervention, due to recurrent PA stenosis.

\section{MATERIALS AND METHODS}

After receiving Institutional Review Board approval with waiver of informed consent, we performed a retrospective review of all intra-operative PA stents placed at our institution between January 1, 1994 and December 31, 2013. Patients were identified through review of the electronic medical record, cardiac 
catheterization reporting systems, and surgical records. Any patient who underwent placement of an intra-operative PA stent was included. Patients were excluded if stent implantation was not attempted or if there was not sufficient documentation to know if stent implantation occurred intra-operatively. Patient data, procedural information (stent type, procedural success and complications), and follow-up data were collected. Procedural success was defined as placement of a stent without the need for removal during the operation.

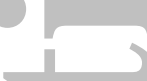

\section{Stent implantation technique:}

All intra-operative PA stents were placed in the operating room on CPB. Minimal dissection of the vessels was performed for isolated stent implantation with retrograde flow within the vessel being managed with pump suckers as needed without obtaining distal vessel control. In the case of pulmonary arterioplasty followed by stent implantation, the PA was fully mobilized with distal control achieved when feasible. Stent diameter, length and position were determined based on pre-surgical angiograms obtained by cardiac catheterization. Stent diameter was determined by the size of the normal adjacent $\operatorname{vessel}(\sim 1 \mathrm{~mm}$ larger than adjacent or distal PA diameter) and no more than 3 times the diameter of the narrowest stenotic PA segment. Whenever possible, stent length was chosen to avoid jailing side branches of distal vessels. Other than direct visual inspection, no other modality, including fluoroscopy, angiography or other visualization techniques (e.g., endoscopy) were utilized. Stent position was defined as ostial/proximal for stents placed prior to the first PA bifurcation and distal for stents placed after the first PA bifurcation. For stents placed in proximal or ostial locations, the proximal end of the stent was manually widened or "flared" into the main PA, helping to secure the stent in place and facilitating future access into the stent lumen during cardiac catheterization. Only balloon-expandable, bare metal stents were used, and whenever possible, medium and large diameter stents were selected (16).

\section{Statistical Analysis:}


Patient and stent characteristics and short- and long-term patient outcomes are described as frequency with percentage for categorical variables and median with interquartile range (IQR) for continuous variables. Freedom from re-intervention in overall and selected subgroups and overall survival were evaluated by Kaplan-Meier curves. Univariate and multivariable Cox regression analyses were performed to identify factors associated with re-intervention. Variables associated with re-intervention in the univariate analysis $(\mathrm{p}<0.1)$ were incorporated into the multivariable analysis. Due to collinearity between age and body surface area at the time of initial stent implantation, only body surface area was included in the multivariable analysis. Hazard ratio (HR) and 95\% confidence interval from the Cox regression were reported. A p-value $<0.05$ was considered statistically significant. Analyses were performed using SAS Version 9.4 (SAS Institute Inc, Cary, North Carolina).

\section{RESULTS}

\section{Patient Characteristics:}

Eighty-one PA stents were placed in 68 patients (Table I). In the majority of patients (84\%), stent implantation was performed as part of a procedure to repair or palliate another cardiac defect (e.g. conduit replacement). Tetralogy of Fallot (TOF) was the most common diagnosis (38\%) and 11 patients (16\%) had major aortopulmonary collateral arteries (MAPCA), representing $42 \%$ of the patients with TOF.

Intra-operative PA stents were most commonly place in the left PA (59\%) and to treat proximal stenoses $(85 \%)$. Medium and large diameter bare metal stents were implanted in 97\% of patients. PALMAZ XL Transhepatic Biliary Stent (58\%. Cordis Endovascular Corporation, Santa Clara, California USA) and ev3 IntraStent ${ }^{\circledR}$ Mega $^{\mathrm{TM}}$ LD Biliary Stent (29\%, ev3 Endovascular, Inc. Plymouth, Minnesota USA) were utilized most frequently.

All patients had previously undergone at least one prior cardiac operation and all patients had undergone at least one prior cardiac catheterization. Twenty-four patients $(35 \%)$ had undergone a prior PA 
intervention, either surgical or catheter-based, on the same PA that received an intra-operative PA stent. Of these, 15 patients (22\%) had undergone at least one prior surgical patch arterioplasty, and 3 patients (4.4\%) had undergone more than 1 arterioplasty. In addition, 12 (18\%) had previous transcatheter interventions, 3 of whom (4.4\%) required multiple prior catheter interventions. In these 12 patients, the median time from catheterization to intra-operative stent placement was 91.5 days (IQR 21 days to 2.5 years), whereas the median time from cardiac catheterization (including diagnostic and interventional procedures) to intra-operative stent placement was 22 days (IQR 1-65 days) for the entire of cohort of patients.

\section{Intra-operative and Hospital Outcomes:}

Stent implantation was acutely successful in all patients but one (99\%). This patient developed a distal pulmonary artery laceration requiring immediate stent removal. The procedural complication rate was $4.4 \%(\mathrm{n}=3)$ and all involved a PA injury requiring repair or patch augmentation.

At hospital discharge, 92\% (54/59) of patients had either no or mild residual stenosis by echocardiogram when excluding patients with an unknown degree of residual stenosis (PAs not visualized or echocardiographic images unavailable) (Table II). Of the 9 patients without a sufficient echocardiogram, 6 underwent a cardiac catheterization between 3 days and 20 months after initial stent placement. In these patients, 4 had no stent stenosis and 2 had mild stent stenosis.

\section{Follow-Up Patient Outcomes (Figure 1):}

During a median follow-up period of 6 years (IQR 0.9-12.7), 30 patients (44\%) underwent re-intervention on their intra-operatively placed PA stent(s) (Table III). The median time to first re-intervention was 2.6 years (interquartile range $0.7-4.4$ years). The first re-intervention was a surgical procedure in 9 (30\%) patients, with all undergoing intra-operative dilation of the existing stent, along with a concomitant surgery. No patient required subsequent surgical pulmonary arterioplasty of the stented PA. Only 1

\section{Catheterization and Cardiovascular Interventions}


patient underwent a surgical procedure for the sole purpose of treating PA stenosis. This patient had single ventricle physiology and because of persistent unilateral lung collapse in the early post-operative period, a lung ventilation perfusion scan was performed which showed no perfusion to unilateral and ipsilateral lung supplied by the stented PA. Therefore, the patient was taken back to the operation room 7 days after the primary surgery with intra-operative stent implantation and_underwent surgical thrombectomy and stent dilation with good long term result. Percutaneous intervention was not attempted. The other 8 patients underwent surgery for other indications (conduit revision [n= 4], Fontan completion $[\mathrm{n}=2]$, Fontan takedown $[\mathrm{n}=1]$ and shunt revision $[\mathrm{n}=1]$. All 8 patients were able to have the existing stent re-dilated.

The first re-intervention was a percutaneous procedure in $21(70 \%)$ patients, which included balloon angioplasty of the existing stent in 14 and placement of a new stent(s) in 7 . For the 7 patients who had new stents placed, the indication was in-stent stenosis $(n=2)$, somatic growth $(n=3)$, stenosis distal to the intra-operative placed stent $(n=2)$, and unknown $(n=1)$.

In the overall cohort, the majority of patients required re-intervention for in-stent stenosis (53\%) and for somatic growth $(30 \%)$. Of note, no patient required re-intervention for either surgical complication or stent fracture at the time of the first re-intervention.

The overall freedom from re-intervention was $83 \%, 74 \%, 51 \%$, and $30 \%$ at $1,2,5$, and 10 years, respectively (Figure 2). The freedom from surgical re-intervention was 95\%, 93\%, 85\%, and 79\% at 1,2, 5 , and 10 years, respectively.

In univariate cox regression analysis, several factors were associated with an increased risk of reintervention (Table IV). These included age less than 18 months (HR 2.97, p=0.005; Figure 3A) and body surface area less than $0.47 \mathrm{~m}^{2}$ (HR 3.20, $\mathrm{p}=0.003$; Figure $3 \mathrm{~B}$ ) at the time of the initial stent

\section{Catheterization and Cardiovascular Interventions}


implantation, a cardiac diagnosis of TOF (compared to non-TOF patients, HR 2.36, $\mathrm{p}=0.02$; Figure $3 \mathrm{C}$ ) and the presence MAPCA (HR 3.56, $\mathrm{p}=0.01$ ). On further examination, the increased hazard seen in the TOF group was driven by the presence of MAPCA, as only TOF patients with MAPCA had a significantly higher risk of-re-intervention compared to non-TOF patients (HR 4.61, $\mathrm{p}=0.003$; Figure 3D). There were no differences in the etiology, sidedness, or location of the pulmonary stenosis in terms of risk for re-intervention. Additionally, prior intervention to treat pulmonary stenosis was not associated with re-intervention. Multivariable analysis showed that cardiac diagnosis was independently associated with re-intervention, controlling for body surface area at the time of initial stent implantation and etiology of PA stenosis (Table V).

There were no deaths or long-term complications related to intra-operative stent placement. However, 6 patients died within 30 days of surgery or prior to hospital discharge (whichever was greater) and 8 additional patients died on long-term follow up (median time between surgery and death of 6.0 years [IQR 2.1-13.6 years]). Thus, the actuarial survival was $89 \%, 83 \%, 80 \%$, and $69 \%$ at $1,5,10$, and 15 years (Figure 4). On univariate analysis, there were no factors associated with a higher mortality risk in our patient cohort.

\section{DISCUSSION}

Intra-operative PA stent implantation is an alternative to percutaneous PA stent implantation and surgical pulmonary arterioplasty in many patients. There are several important advantages of intra-operative compared to transcatheter stent implantation, including the ability to implant stents that can be dilated ultimately to adult-size in small patients, while avoiding injury to peripheral vessels and hemodynamic compromise. In addition, because there is direct access and visualization of the branch pulmonary arteries, the stents can be positioned with flaring of the proximal ends of the stent to facilitate future percutaneous re-dilation or subsequent stent re-implantation. The flaring increases the chance that a wire and catheter enter the stent lumen, rather than through a side-strut. Furthermore, intra-operative PA

\section{Catheterization and Cardiovascular Interventions}


stenting eliminates radiation exposure associated with transcatheter PA stenting. The disadvantages of intra-operative PA stent implantation include the need for a median sternotomy, a high likelihood of patients requiring future stent dilation either due to somatic growth or in-stent stenosis, exposure to cardiopulmonary bypass, and the possibility of jailing side branches of the distal PA. Importantly, these last two disadvantages may be overcome using a hybrid approach with intra-operative fluoroscopy.

Intra-operative stent placement can be performed successfully in most patients. Of patients who underwent attempted stent placement, a stent was implanted in $99 \%$ of patients. Ninety-two percent of patients had $\leq$ mild residual pulmonary stenosis by echocardiography at hospital discharge and for those patients without an echocardiogram but subsequent PA angiography, $91 \%$ of patients had $\leq$ mild residual stenosis. Unfortunately, not all patients underwent subsequent angiography or additional imaging, like ventilation perfusions scans or cardiac MRI, to better quantitate procedural success. Given the retrospective nature of our study, this data is lacking but will be an important indication in any future prospective studies examining intra-operative PA stenting outcomes.

Additionally, intra-operative PA stent placement can be performed safely. The rates of vascular injury and stent embolization are lower than that reported for percutaneous stent implantation (17). In our series, the total stent related complication rate was $4.4 \%$, whereas the stent-related complication rate was $10 \%$ for percutaneous PA stent placement from a multi-center registry study (17) and $0-40 \%$ reported in a review article summarizing various reports of percutaneous PA stent implantation between 1991 and 2010 (18). Importantly, no patient died during a procedure in which intra-operative stent placement was performed, and there were no deaths as a result of a complication from intra-operative stent placement. Although the 30-day mortality rate was high at $8.8 \%$, this was related to the high-risk nature of the patients in whom intra-operative stent placement was performed. Three patients underwent intraoperative PA stent placement while already on ECMO support. All underwent successful stent implantation but all were unable to wean from ECMO support and died. Two other patients had care

\section{Catheterization and Cardiovascular Interventions}


withdrawn for severe global hypoxic-ischemic brain injuries after right ventricle to pulmonary artery conduit replacement operations with concomitant intra-operative PA stent implantation. Lastly, one patient underwent a neonatal repair for TOF and absent pulmonary valve, and later underwent intraoperative stent implantation at 3 months of life. The patient died at 1 year of age, 9 months after stent implantation due to complication from ventilator dependence related to severe bronchomalacia.

Eight patients died during long-term follow-up. Seven patients had single ventricle physiology and one had TOF with pulmonary atresia and MAPCA.

In our experience, nearly $44 \%$ of patients require re-intervention of the PA stent during follow-up, and $22 \%$ of patients require more than one re-intervention. Our 2- and 5-year freedom from re-intervention rates of $74 \%$ and $51 \%$ were nearly identical to those found in the one other study examining the longterm outcomes following intraoperative PA stent placement, in which the 2 and 5 year rates were $68 \%$ and 49\%, respectively (15). This is in close approximation with reports of percutaneous PA stent placement, where re-intervention rates for stent dilation range from $26-66 \%$ during follow-up periods ranging from 0.9 to 7.2 years (18).

Re-interventions are expected whenever stents are placed in children given anticipated somatic growth. In our study, $30 \%$ of re-interventions were performed for somatic growth. To support this further, two of the main risk factors for re-intervention were age less than 18 months and body surface area less than 0.47 $\mathrm{m}^{2}$ at initial implant.

A cardiac diagnosis of TOF with MAPCA is the other main risk factor for re-intervention. This is not an unexpected finding, as the PAs in patients with MAPCA are often hypoplastic and require multiple interventions, especially during the first several years of life, compared to TOF patients without MAPCA $(19,20)$. Furthermore, patients with MAPCA are at a higher risk of developing in-stent stenosis 
secondary to neointimal proliferation (21). These patients need close monitoring, and frequent reintervention should be expected.

Fortunately, the majority of patients who require re-intervention after placement of an intra-operative PA stent can undergo re-intervention via percutaneous techniques. We believe that this is facilitated by placing stents that can be serially balloon dilated to adult sizes and to flaring the proximal edge of the stent.

In this study, stents were placed on CPB by direct visualization alone, using pre-surgical angiography to determine stent sizes. The disadvantages to this approach include exposure to CPB and the inability to visualize, avoid, and/or treat side vessel jailing or vessel wall injury during stent implantation. In our cohort, the median CPB duration was 50 minutes (IQR 38-90 minutes) for patients undergoing isolated intra-operative PA stenting. Although difficult to determine CPB duration related to stent implantation when performed during additional cardiac procedures requiring $\mathrm{CPB}$, anecdotally, most stents can be prepared and implanted in less than 15 minutes. There are alternative methods for placing intra-operative PA stents, such as hybrid-implantation, using intra-operative angiography and fluoroscopy. This is particularly useful for placing stents distally or at PA bifurcations. This helps to avoid jailing side branches and facilitates opening the side struts into side branches, if needed. Additionally, hybrid stent implantation can be done without using $\mathrm{CPB}$, thereby eliminating the deleterious effects of bypass in patients not undergoing concomitant procedures. This does, however, expose patients to ionizing radiation. Thus, the risks and benefits of each modality should be considered on an individual basis. $>1$

Our current practice is to utilize intra-operative PA stent placement in patients with significant PA stenosis that is not amenable to balloon angioplasty or surgical patch arterioplasty (because of the nature of the lesion and/or poor response to prior angioplasty or arterioplasty) and who are undergoing a concomitant surgical procedure. Additionally, intra-operative PA stent placement is performed in 
patients in whom a transcatheter approach is not feasible, either due to the size of the peripheral vasculature or due to hemodynamic instability during attempted stent implantation. Importantly, there have been many advances in pre-mounted stent technology in the last 5 years, allowing implantation using much smaller sheath sizes than are needed for unmounted large bare metal stents. Therefore the ultimate desired size of the stent needs to be taken into account when deciding on the appropriate therapy for a patient.

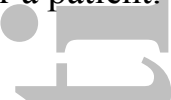

\section{Limitations:}

Due to the retrospective nature of this study, it was not possible to re-create the decision-making that went into performing surgical arterioplasty versus surgical or percutaneous stent implantation. We can make some inferences, however the exact indication for intra-operative stent implantation was sometimes unknown, and, thus, selection bias could impact our results. Likewise, stent choice and size, as well as the indications for re-intervention are difficult to delineate retrospectively.

\section{CONCLUSION}

Intra-operative PA stent implantation is technically feasible with low procedural, stent-related complications. The rates of central vascular injury and stent embolization are lower than that reported for percutaneous stent implantation (17) and radiation exposure is eliminated. Similar to what is reported with percutaneous stent implantation, re-intervention is common. When utilized in younger patients and patients with MAPCA, re-intervention for either development of in-stent stenosis and/or somatic growth should be expected. This study expands the knowledge of intra-operative PA stent placement and the impact of stents placed largely during childhood on late outcomes.

\section{Acknowledgements and Disclosures: None}




\section{References}

1. Bacha EA, Kreutzer J. Comprehensive management of branch pulmonary artery stenosis. Journal of interventional cardiology 2001;14(3):367-375.

2. Patel ND, Kenny D, Gonzalez I, Amin Z, Ilbawi MN, Hijazi ZM. Single-center outcome analysis comparing reintervention rates of surgical arterioplasty with stenting for branch pulmonary artery stenosis in a pediatric population. Pediatric cardiology 2013.

3. Trant CA, Jr., O'Laughlin MP, Ungerleider RM, Garson A, Jr. Cost-effectiveness analysis of stents, balloon angioplasty, and surgery for the treatment of branch pulmonary artery stenosis. Pediatric cardiology 1997;18(5):339-344.

4. McGoon DC, Kincaid OW. Stenosis of branches of the pulmonary artery: Surgical repair. The Medical clinics of North America 1964;48:1083-1088.

5. Vida VL, Rito ML, Zucchetta F, Biffanti R, Padalino MA, Milanesi O, Stellin G. Pulmonary artery branch stenosis in patients with congenital heart disease. Journal of cardiac surgery 2013;28(4):439-445.

6. Bokenkamp R, Blom NA, De Wolf D, Francois K, Ottenkamp J, Hazekamp MG. Intraoperative stenting of pulmonary arteries. European journal of cardio-thoracic surgery : official journal of the European Association for Cardio-thoracic Surgery 2005;27(4):544-547.

7. Coles JG, Yemets I, Najm HK, Lukanich JM, Perron J, Wilson GJ, Rabinovitch M, Nykanen DG, Benson LN, Rebeyka IM, Trusler GA, Freedom RM, Williams WG. Experience with repair of congenital heart defects using adjunctive endovascular devices. The Journal of thoracic and cardiovascular surgery 1995;110(5):1513-1519; discussion 1519-1520.

8. Holzer RJ, Chisolm JL, Hill SL, Olshove V, Phillips A, Cheatham JP, Galantowicz M . "Hybrid" stent delivery in the pulmonary circulation. The Journal of invasive cardiology 2008;20(11):592-598.

9. Menon SC, Cetta F, Dearani JA, Burkhart HA, Cabalka AK, Hagler DJ. Hybrid intraoperative pulmonary artery stent placement for congenital heart disease. The American journal of cardiology 2008;102(12):1737-1741. 
10. Mitropoulos FA, Laks H, Kapadia N, Gurvitz M, Levi D, Williams R, Plunkett M. Intraoperative pulmonary artery stenting: An alternative technique for the management of pulmonary artery stenosis. The Annals of thoracic surgery 2007;84(4):1338-1341; discussion 1342.

11. Ungerleider RM, Johnston TA, O'Laughlin MP, Jaggers JJ, Gaskin PR. Intraoperative stents to rehabilitate severely stenotic pulmonary vessels. The Annals of thoracic surgery 2001;71(2):476-481. 12. Mendelsohn AM, Bove EL, Lupinetti FM, Crowley DC, Lloyd TR, Fedderly RT, Beekman RH. Intraoperative and percutaneous stenting of congenital pulmonary artery and vein stenosis. Circulation 1993;88(5 Pt 2):II210-217.

13. Lynch W, Boekholdt SM, Hazekamp MG, de Winter RJ, Koolbergen DR. Hybrid branch pulmonary artery stent placement in adults with congenital heart disease. Interactive cardiovascular and thoracic surgery 2015;20(4):499-503.

14. Sridhar A, Subramanyan R, Premsekar R, Chidambaram S, Agarwal R, Manohar SRK, Cherian KM. Hybrid intraoperative pulmonary artery stenting in redo congenital cardiac surgeries. Indian heart journal 2014;66(1):45-51.

15. Angtuaco MJ, Sachdeva R, Jaquiss RD, Morrow WR, Gossett JM, Fontenot E, Seib PM. Longterm outcomes of intraoperative pulmonary artery stent placement for congenital heart disease. Catheter Cardiovasc Interv 2011;77(3):395-399.

16. Peters B, Ewert P, Berger F. The role of stents in the treatment of congenital heart disease:

Current status and future perspectives. Annals of pediatric cardiology 2009;2(1):3-23.

17. Holzer RJ, Gauvreau K, Kreutzer J, Leahy R, Murphy J, Lock JE, Cheatham JP, Bergersen L. Balloon angioplasty and stenting of branch pulmonary arteries: Adverse events and procedural characteristics: Results of a multi-institutional registry. Circ Cardiovasc Interv 2011;4(3):287-296.

18. Krisnanda C, Menahem S, Lane GK. Intravascular stent implantation for the management of pulmonary artery stenosis. Heart, lung \& circulation 2013;22(1):56-70.

19. Carotti A, Albanese SB, Flipelli S, Rava L, Guccione P, Pongiglione G, Di Donato RM . Determinants of outcome after surgical treatment of pulmonary atresia with ventricular septal defect and 
major aortipulmonary collateral arteries. The Journal of thoracic and cardiovascular surgery 2010;140(5):1092-1103.

20. Amark KM, Karamlou T, O’Carroll A, MacDonald C, Freedom RM, Yoo SH, Williams WG, Van Arsdell GS, Caldaerone CA, McCrindle BW. Independent factors associated with mortality, reintervention, and achievement of complete repair in children with pulmonary atresia with ventricular septal defect. JACC 2006;47(7):1149-1156.

21. Hallbergson A, Lock JE, Marshall AC. Frequency and risk of in-stent stenosis following pulmonary artery stenting. Am J Cardiol 2014;113(3):541-545.
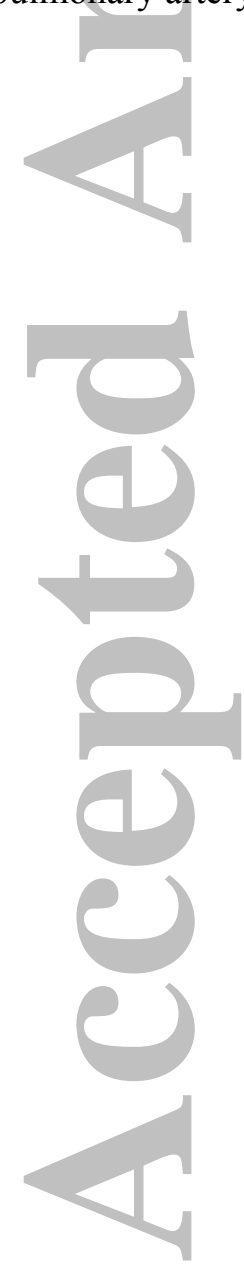


\section{Figure Legends:}

1: Patient outcomes flow chart

2: Freedom from first re-intervention in the overall cohort stratified by the type of re-intervention (surgical versus percutaneous). The median time to re-intervention is 5.3 years for the overall cohort, as illustrated by the dotted line. The $(*)$ indicates that no patient in any cohort was at risk after 10 years, and therefore, the figure was truncated to only include the first 10 years of follow-up.

3: Freedom from first re-intervention stratified by various clinical characteristics, including age (3A), body surface area (3B), cardiac diagnosis (3C), and cardiac diagnosis with presence of MAPCAs (3D). Median freedom from re-intervention is represented for each group by the dotted lines.

Abbreviations: BSA, body surface area; MAPCA, multiple aorto-pulmonary collateral arteries; non-TOF, diagnosis other than tetralogy of Fallot; TOF, tetralogy of Fallot.

4: Overall survival of the entire cohort $(n=68)$

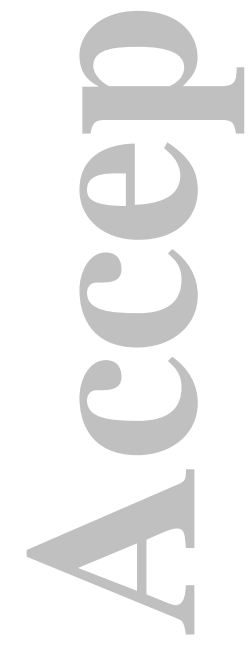


Table I: Patient and clinical characteristics $(n=68)$

\begin{tabular}{|c|c|}
\hline Male sex & $48(70.6)$ \\
\hline Caucasian race & $50(73.5)$ \\
\hline Age $^{\mathrm{a}}$, years & $2.6(1.2-7.6)$ \\
\hline$<18$ months & $22(32.4)$ \\
\hline$\geq 18$ & $46(67.6)$ \\
\hline Weight $^{\mathrm{a}}, \mathrm{kg}$ & $12.4(8.7-20.4)$ \\
\hline Height $^{\mathrm{a}}, \mathrm{cm}$ & $85.5(74.5-123)$ \\
\hline Body surface area ${ }^{\mathrm{a}}, \mathrm{m} 2$ & $0.54(0.42-0.84)$ \\
\hline$<0.47 \mathrm{~m} 2$ & $25(36.8)$ \\
\hline & $43(63.2)$ \\
\hline $\begin{array}{c}\text { Cardiac diagnosis } \\
\text { TOF }\end{array}$ & $26(382)$ \\
\hline With pulmonary stenosis & $8(11.8)$ \\
\hline With pulmonary atresia & $18(26.5)$ \\
\hline$\{$ With MAPCAs & $11(16.2)\}$ \\
\hline HLHS & $13(19.1)$ \\
\hline Truncus Arteriosus & $7(10.3)$ \\
\hline Other single ventricle defects & $4(5.9)$ \\
\hline Double outlet right ventricle & $3(4.4)$ \\
\hline 1-TGA & $3(4.4)$ \\
\hline d-TGA & $2(2.9)$ \\
\hline AVSD & $1(1.5)$ \\
\hline Other & $9(13.2)$ \\
\hline
\end{tabular}


Indication for surgery

Repair or palliation of another cardiac defect

Isolated branch pulmonary stenosis

$11(16.2)$

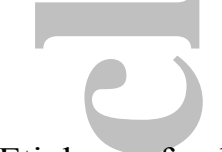

Etiology of pulmonary stenosis

Acquired (including post-surgical)

Congenital

$11(16.2)$

Affected pulmonary artery

Left

$40(58.8)$

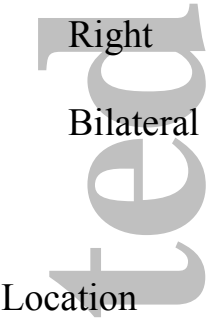

$15(22.1)$

$13(19.1)$

Ostial/Proximal

$58(85.3)$

Distal

$8(11.8)$

Unknown

$2(2.9)$

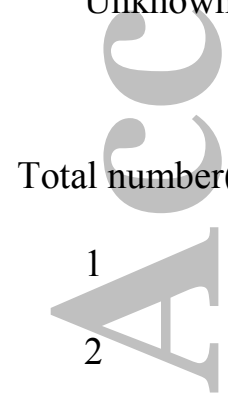

$$
2(2.9)
$$

3

$23(33.8)$

29 (42.6)

$13(19.1)$

4

$3(4.4)$

Prior pulmonary artery interventions

$24(35.3)$

Catheterization and Cardiovascular Interventions

This article is protected by copyright. All rights reserved. 
Surgical

Transcatheter
$15(22.1)$

$12(17.6)$

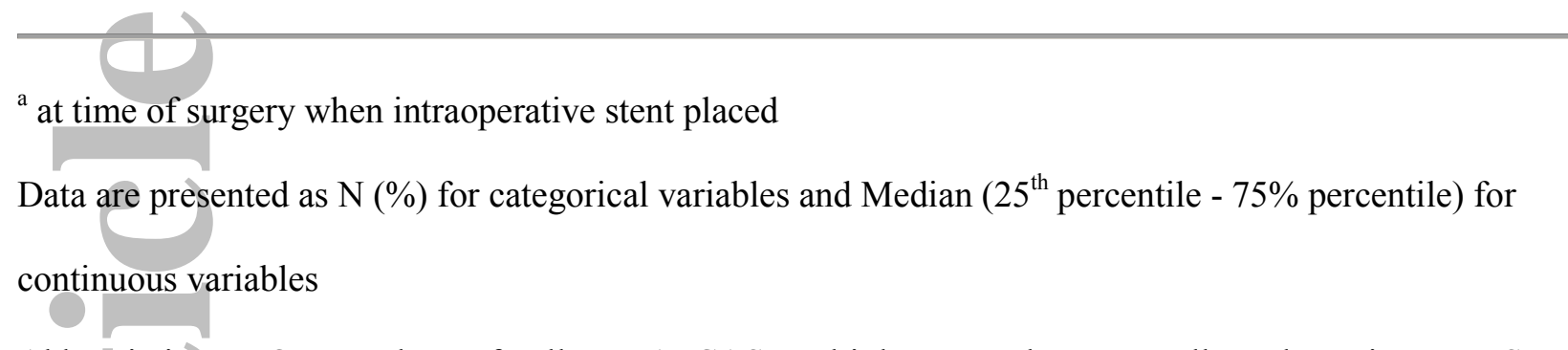

Abbreviations: TOF, tetralogy of Fallot; MAPCAS, multiple aortopulmonary collateral arteries; HLHS, hypoplastic left heart syndrome; TGA, transposition of the great arteries; AVSD, atrioventricular septal defect.
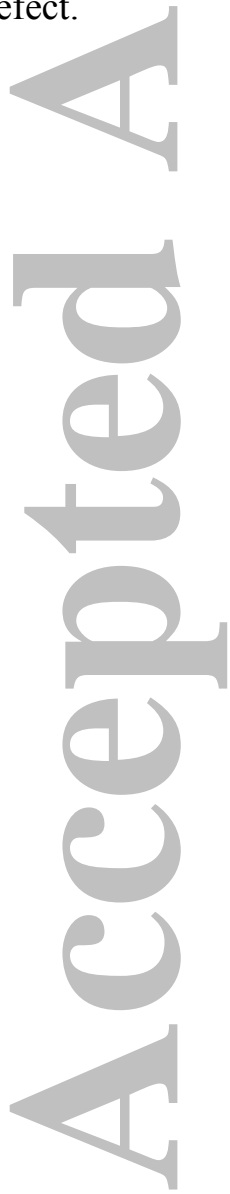
Table II: Intra-operative and hospital outcomes

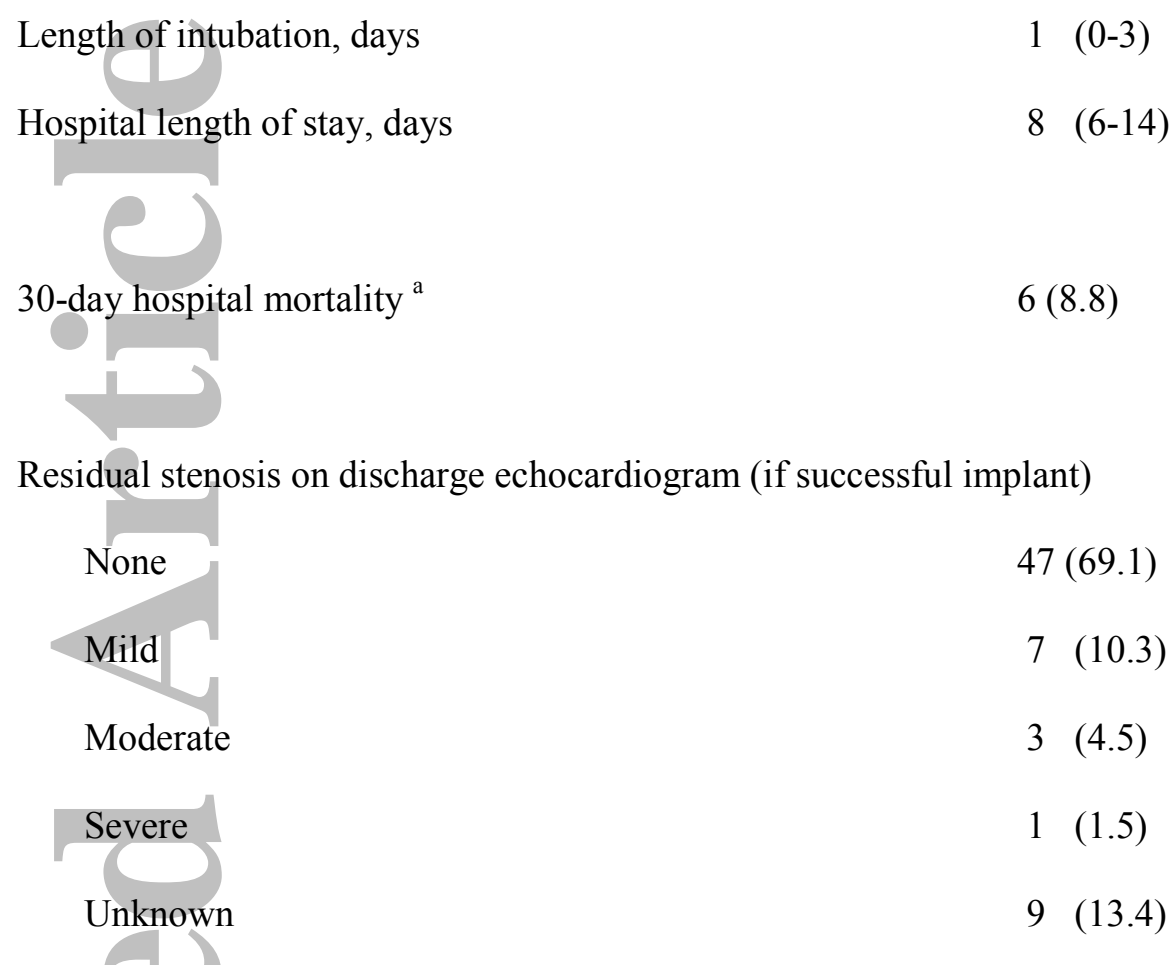

taving

a 30 -day mortality refers to death within 30 days of surgery or prior to hospital discharge, whichever is greater

Data are presented as N (\%) for categorical variables and Median $\left(25^{\text {th }}\right.$ percentile $-75 \%$ percentile $)$ for continuous variables

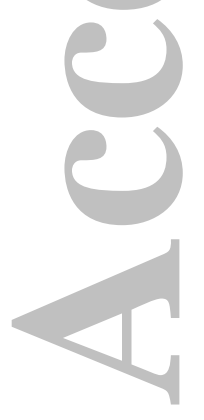


Table III: Long-term patient outcomes

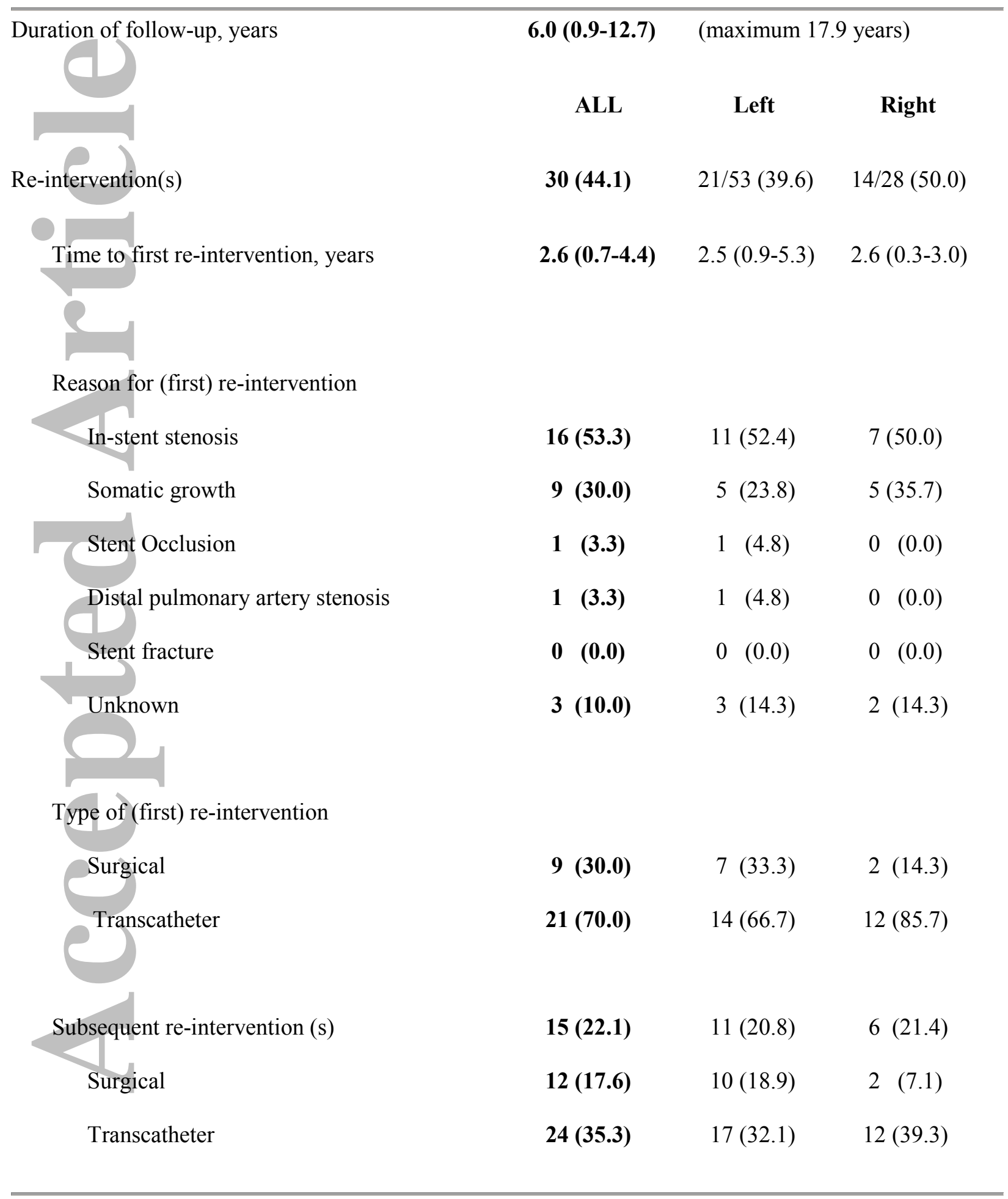

Data are presented as N (\%) for categorical variables and Median $\left(25^{\text {th }}\right.$ percentile $-75 \%$ percentile $)$ for continuous variables 
Table IV: Factors associated with re-intervention

\begin{tabular}{|c|c|c|c|c|c|}
\hline & \multicolumn{2}{|c|}{ Re-intervention } & \multirow[b]{2}{*}{ HR } & \multirow[b]{2}{*}{$95 \% \mathrm{CI}$} & \multirow[b]{2}{*}{ p-value ${ }^{a}$} \\
\hline Characteristics & $\begin{array}{l}\text { Yes } \\
(\mathrm{N}=30)\end{array}$ & $\begin{array}{c}\text { No } \\
(\mathrm{N}=38)\end{array}$ & & & \\
\hline \multicolumn{6}{|l|}{ Age at surgery, years } \\
\hline$<18$ months & $13(43.3)$ & $9(23.7)$ & 2.97 & $1.40,6.30$ & 0.005 \\
\hline$\geq 18$ months & $17(56.7)$ & $29(76.3)$ & Ref & & \\
\hline \multicolumn{6}{|l|}{ Body surface area, $\mathrm{m}^{2}$} \\
\hline$<0$. & $14(46.7)$ & $11(28.9)$ & 3.20 & $1.48,6.89$ & 0.003 \\
\hline$\geq 0$. & $16(53.3)$ & $27(71.1)$ & Ref & & \\
\hline Cardiac diagnosis & & & & & 0.01 \\
\hline TOF with MAPCA & $6(20.0)$ & $4(10.5)$ & 4.61 & $1.71,12.5$ & 0.003 \\
\hline TOF without MAPCA & $8(26.7)$ & $8(21.1)$ & 1.76 & $0.75,4.15$ & 0.19 \\
\hline Non- & $16(53.3)$ & $26(68.4)$ & Ref & & \\
\hline TOF vs. Non-TOF & $14(46.7)$ & $12(31.6)$ & 2.36 & $1.14,4.89$ & 0.02 \\
\hline MAPCA vs. Non-MAPCA & $6(20.0)$ & $5(13.2)$ & 3.56 & $1.37,9.21$ & 0.01 \\
\hline Indication for surgery & & & & & 0.84 \\
\hline Isolated branch PS & $6(20.0)$ & $5(13.2)$ & 1.10 & $0.44,2.74$ & \\
\hline Repair of other defect & $24(80.0)$ & $33(86.8)$ & Ref & & \\
\hline
\end{tabular}


Etiology of pulmonary artery stenosis

0.09

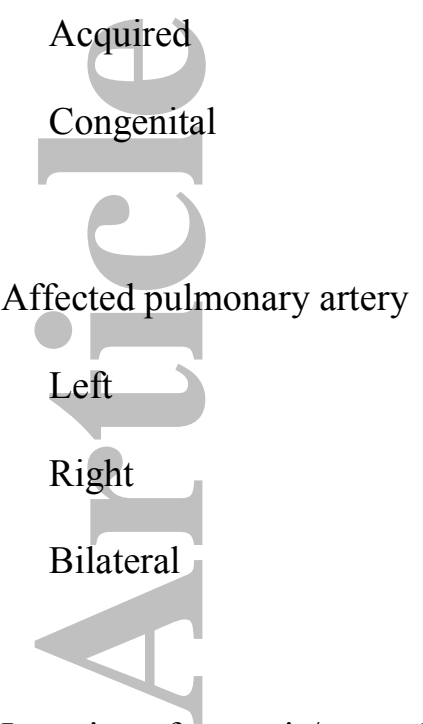

$24(80.0)$

33 (86.8) Ref

$6(20.0)$

5 (13.2)

$2.23 \quad 0.88,5.65$

Location of stenosis/stent placement

$15(50.0)$

$25(65.8) \quad$ Ref

$9(30.0)$

$6(15.8)$

$2.05 \quad 0.89,4.72$

$6(20.0)$

$7(18.4)$

$2.47 \quad 0.93,6.60$

Ostial or Proximal

$25(83.3)$

$33(86.8)$

Ref

Distal

$5(16.7)$

$3(7.9)$

$1.80 \quad 0.69,4.75$

$0(0.0)$

$2(5.3)$

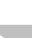

Prior intervention

$9(30.0)$

$15(39.5)$

$0.84 \quad 0.38,1.84$

0.09

0.07

0.66

0.10

0.23

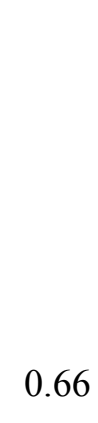

\section{${ }^{a} \mathrm{P}$-value from univariate Cox regression.}

Data are presented as N (\%)

Abbreviations: HR, hazard ratio; CI, confidence interval; Ref, reference category; TOF, tetralogy of Fallot; MAPCA, multiple aortopulmonary collateral arteries; PS, pulmonary stenosis. 
Table V: Multivariable analysis of factors associated with re-intervention

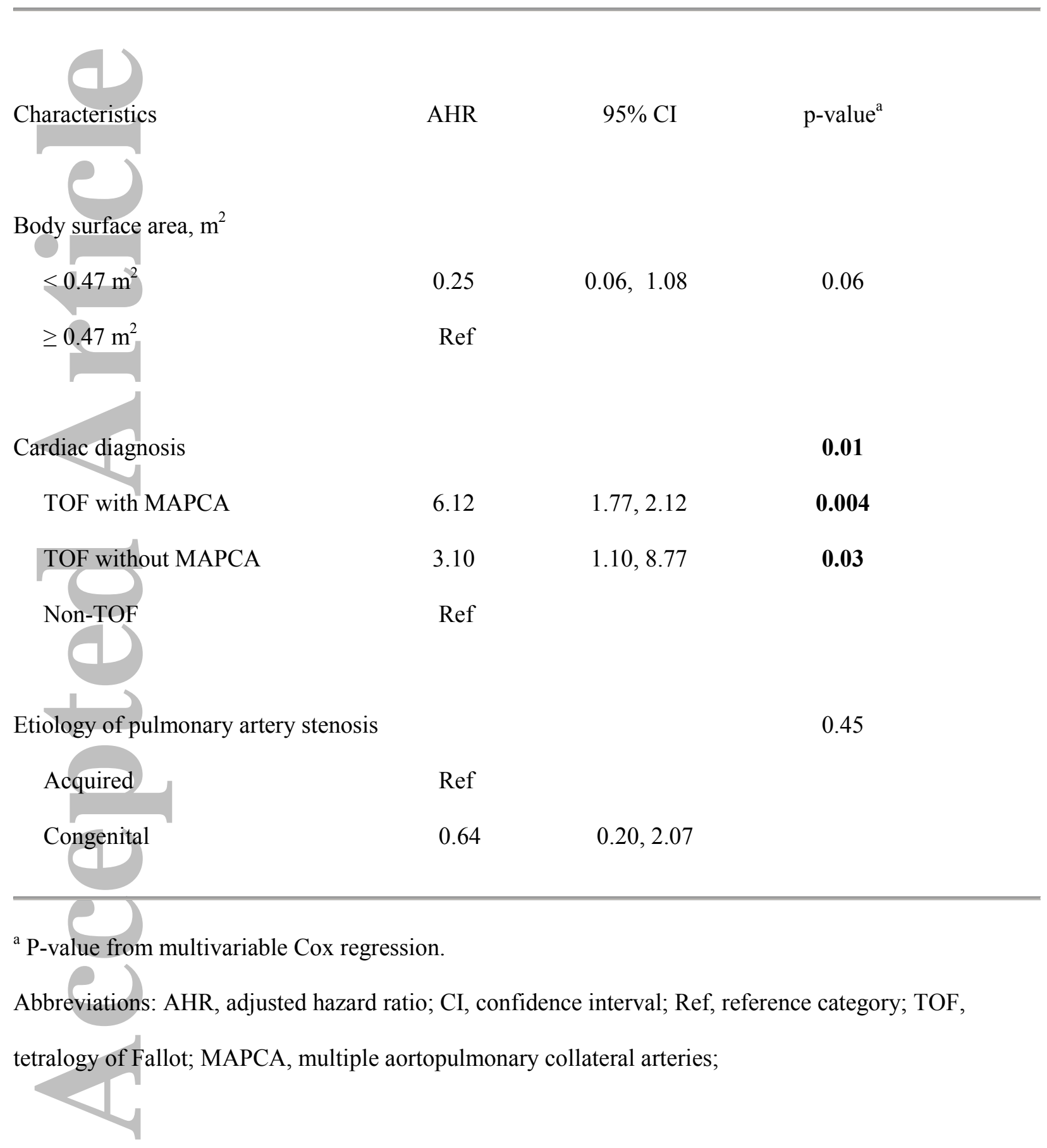




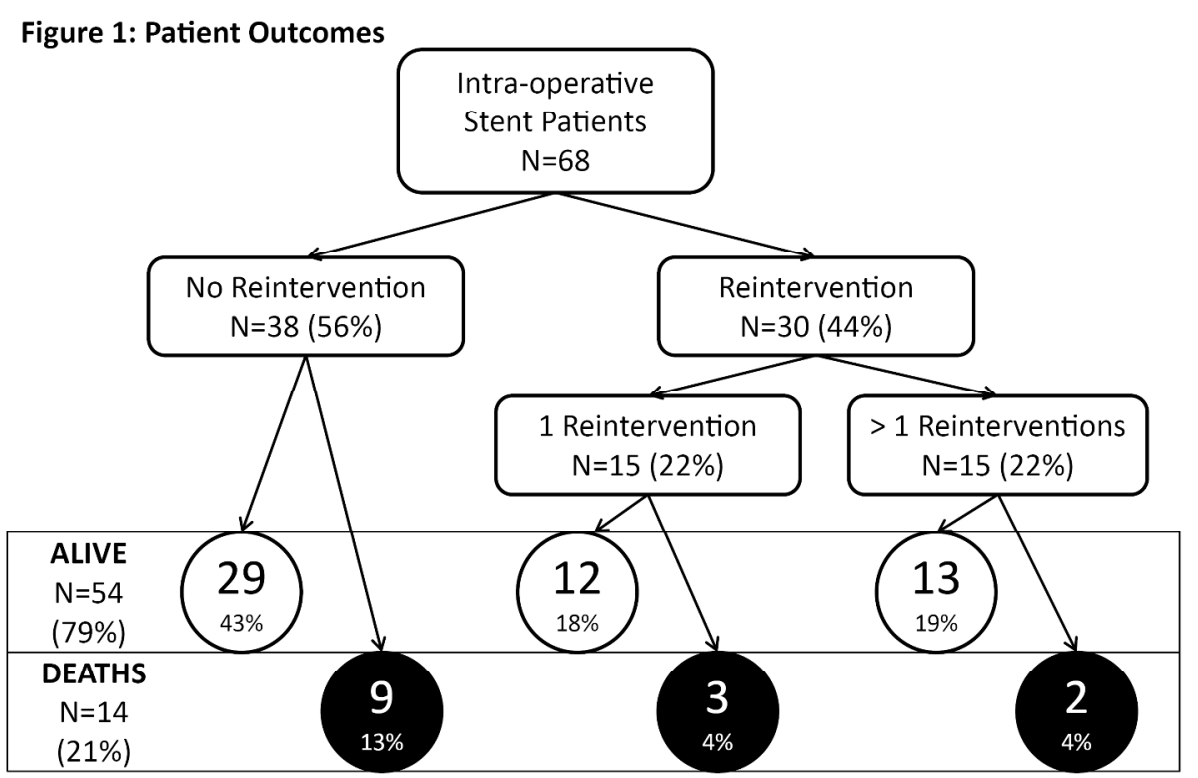

Figure 1: Patient outcomes flow chart Figure 1 254x190mm (300 x 300 DPI) 


\section{Figure 2: Freedom from (First) Re-intervention}

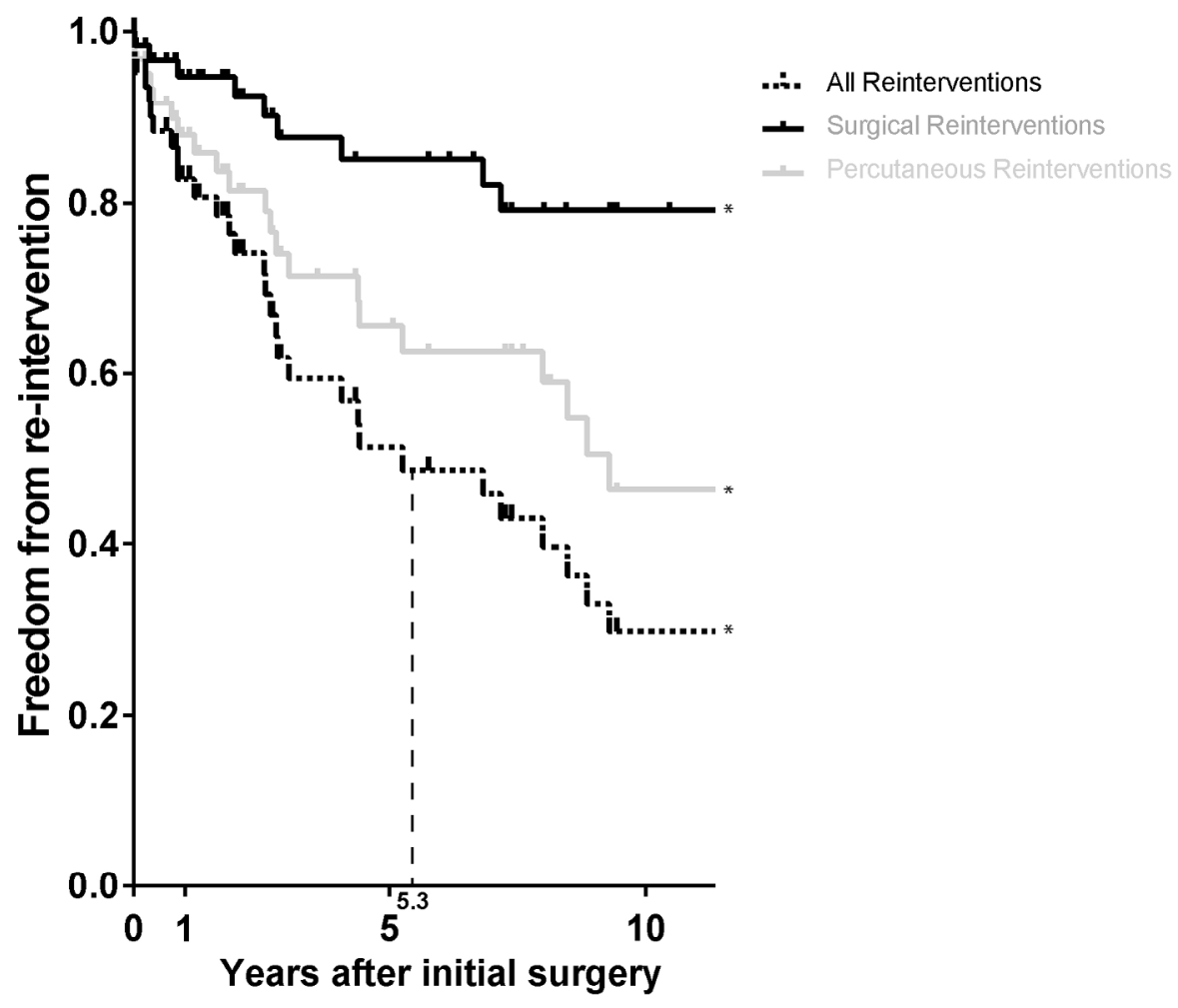

Figure 2: Freedom from first re-intervention in the overall cohort stratified by the type of re-intervention (surgical versus percutaneous)

$$
\text { Figure } 2
$$

$173 \times 153 \mathrm{~mm}(300 \times 300 \mathrm{DPI})$

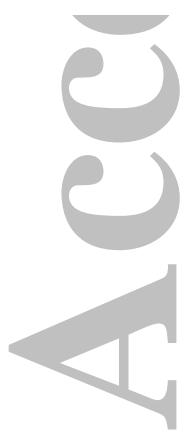




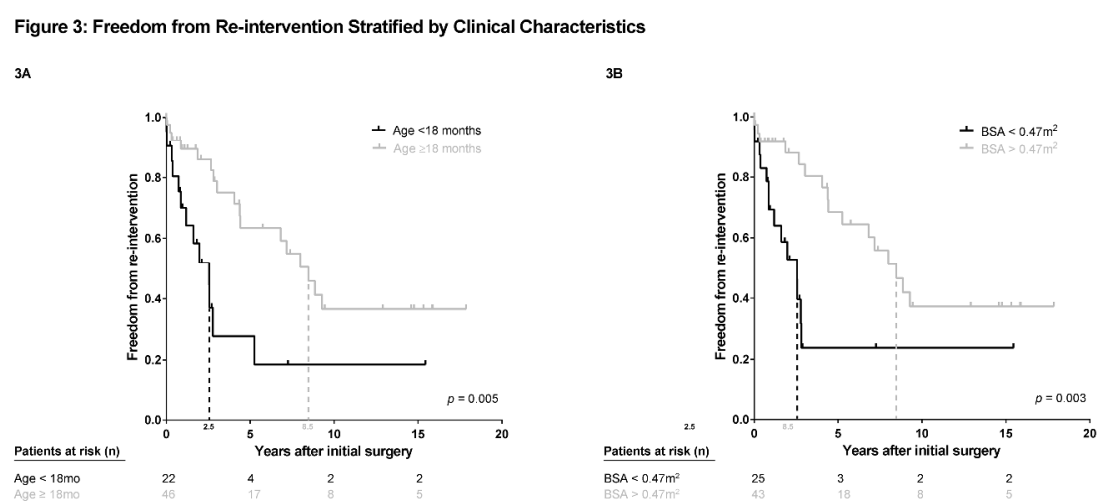

$3 c$

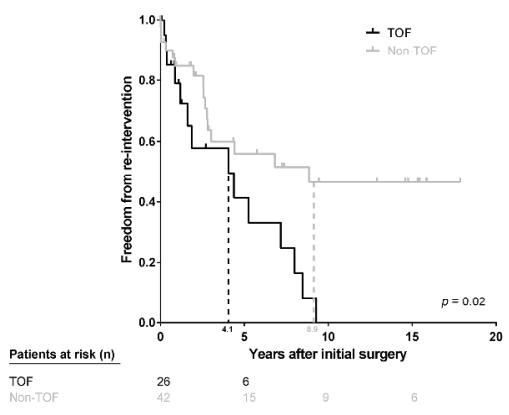

30

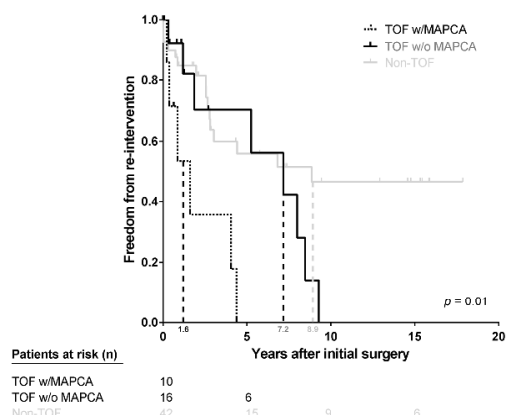

Figure 3: Freedom from first re-intervention stratified by various clinical characteristics, including age (3A), body surface area (3B), cardiac diagnosis (3C), and cardiac diagnosis with presence of MAPCAs (3D) Figure 3

$525 \times 397 \mathrm{~mm}(300 \times 300 \mathrm{DPI})$

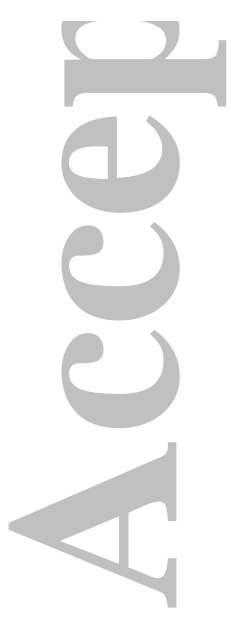




\section{Figure 4: Survival}

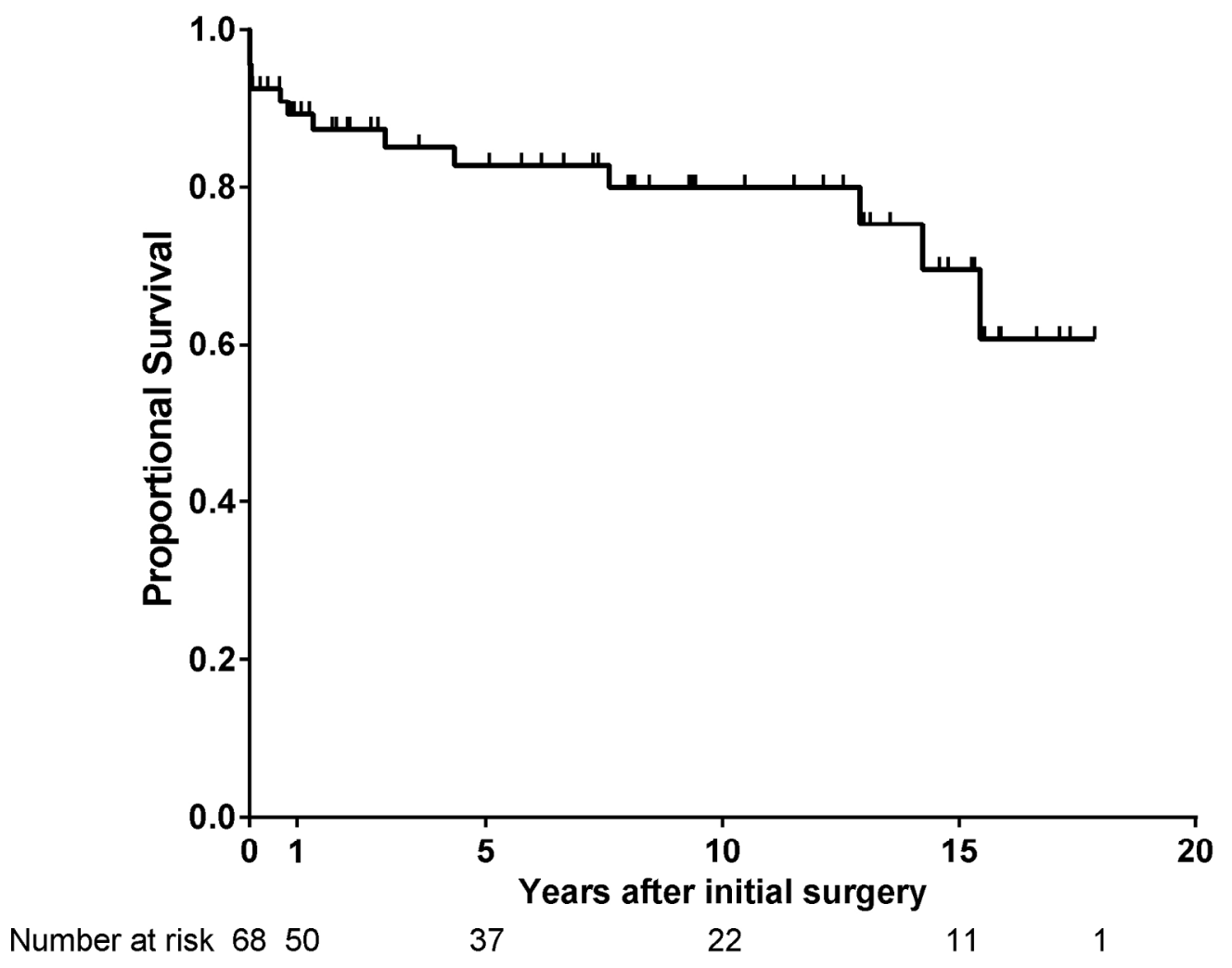

Figure 4: Overall survival of the entire cohort $(n=68)$

Figure 4

$174 \times 160 \mathrm{~mm}(300 \times 300 \mathrm{DPI})$ 


\section{Twenty Years of Experience with Intra-operative Pulmonary Artery Stenting}

Running Head: Intra-operative pulmonary artery stents

Jeffrey D. Zampi, MD ${ }^{1}$, Emefah Loccoh ${ }^{2}$, Aimee K. Armstrong, MD ${ }^{3}$, Sunkyung Yu, MS ${ }^{1}$, Ray Lowery ${ }^{1}$, Albert P. Rocchini, $\mathrm{MD}^{1}$, and Jennifer C. Hirsch-Romano, MD, $\mathrm{MS}^{4}$

${ }^{1}$ University of Michigan Congenital Heart Center, C.S. Mott Children's Hospital, 1540 East Hospital Drive, floor 11, Ann Arbor, Michigan 48109. Division of Pediatric Cardiology

${ }^{2}$ Ohio State University College of Medicine, 370 West 9th Avenue, Columbus, Ohio 43210.

${ }^{3}$ Nationwide Children's Hospital, 700 Children's Drive, Columbus, Ohio 43205. Division of Pediatric

\section{Cardiology}

${ }^{4}$ University of Michigan Congenital Heart Center, C.S. Mott Children's Hospital, 1540 East Hospital Drive, floor 11, Ann Arbor, Michigan 48109. Department of Cardiac Surgery

Keywords: Congenital heart disease, stenting technique, hybrid revascularization (peripheral)

\section{Word Count: $\underline{4254}$}

Corresponding Author: Jeffrey Zampi, MD

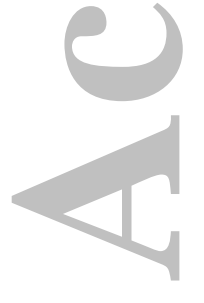

Assistant Professor of Pediatric Cardiology, University of Michigan Congenital

Heart Center, C.S. Mott Children's Hospital Floor 11, Room 715Z

1540 E. Hospital Drive, Ann Arbor, MI 48109-4204

Email: jzampi@med.umich.edu, Phone: 734-936-3813,Fax: 734-936-9470 


\begin{abstract}
Objectives: To describe our 20-year experience with intra-operative pulmonary artery stent placement and evaluate long-term patient outcomes, specifically the need and risk factors for re-intervention.

Background: Intra-operative pulmonary artery stent placement is an alternative to surgical patch arterioplasty and percutaneous angioplasty or stent placement to treat branch pulmonary artery (PA) stenosis.
\end{abstract}

Methods: We performed a retrospective review of all intra-operative pulmonary artery stents placed at our institution from 1994-2013. Patient and stent characteristics and outcome data were collected. Risk factors associated with re-intervention were identified using univariate cox regression analysis.

Results: Eighty-one PA stents were placed in 68 patients. The procedural complication rate was 4.4\%. During a median follow-up period of 6 years (interquartile range (IQR) $0.9-12.7$ ), 30 patients (44\%) underwent re-intervention on the stented PA with a median time to first re-intervention of 2.6 years (IQR 0.7-4.4 years). The first re-intervention was surgical in 30\% and catheter-based in $70 \%$. Risk factors for re-intervention included age $<18$ months (Hazard ratio [HR] 2.97, $\mathrm{p}=0.005$ ) and body surface area $<0.47$ $\mathrm{m}^{2}(\mathrm{HR} 3.20, \mathrm{p}=0.003)$ at the time of stent implantation, and the presence of multiple aorto-pulmonary collaterals in patients with tetralogy of Fallot (HR 4.61, $\mathrm{p}=0.003)$.

Conclusions: Intra-operative PA stent implantation is a safe and effective alternative to percutaneous stent implantation and offers several advantages, including the ability to implant adult-size stents in small patients while avoiding injury to peripheral vessels, to position stents to facilitate future percutaneous stent re-dilation, and to access the PAs directly, which eliminates radiation exposure.

Abstract Word Count: 250 


\section{INTRODUCTION}

Branch pulmonary artery (PA) stenosis is a relatively common problem in congenital heart disease.

Percutaneous techniques have reduced the need for surgical pulmonary arterioplasty and are as effective as surgical arterioplasty while avoiding cardiopulmonary bypass (CPB) (1-3). However, many patients

still require operative repair either due to the morphology of the stenosis, inadequate response to

percutaneous techniques, small patient size prohibiting safe or effective percutaneous intervention, or the need for concomitant repair of other surgical defects (1). Re-intervention for recurrent stenosis after surgical pulmonary arterioplasty is required in $48-64 \%$ of patients and has not changed significantly over the last 40 years (2-5). Because of early restenosis, these patients can require multiple surgical or catheterization procedures early in childhood, exposing them to the risks of repeated sternotomy, $\mathrm{CPB}$, and/or radiation, to name a few.

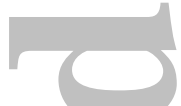

Intra-operative PA stent placement is an alternative approach. This procedure has been shown to be safe with excellent short-term efficacy (6-14). It can allow for implantation of stents that can be dilated to adult size that would be difficult to place percutaneously in small children, while avoiding ionizing radiation exposure from cardiac catheterization procedures. However, longer-term data on the outcomes of intra-operative PA stenting are limited (15).

We sought to describe our experience with intra-operative PA stent placement over the last 20 years and to examine long-term patient outcomes, specifically focusing on the incidence of and risk factors for reintervention, due to recurrent PA stenosis.

\section{MATERIALS AND METHODS}

After receiving Institutional Review Board approval with waiver of informed consent, we performed a retrospective review of all intra-operative PA stents placed at our institution between January 1, 1994 and December 31, 2013. Patients were identified through review of the electronic medical record, cardiac 
catheterization reporting systems, and surgical records. Any patient who underwent placement of an intra-operative PA stent was included. Patients were excluded if stent implantation was not attempted or if there was not sufficient documentation to know if stent implantation occurred intra-operatively. Patient data, procedural information (stent type, procedural success and complications), and follow-up data were collected. Procedural success was defined as placement of a stent without the need for removal during the operation.

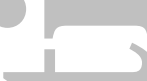

\section{Stent implantation technique:}

All intra-operative PA stents were placed in the operating room on CPB. Minimal dissection of the vessels was performed for isolated stent implantation with retrograde flow within the vessel being managed with pump suckers as needed without obtaining distal vessel control. In the case of pulmonary arterioplasty followed by stent implantation, the PA was fully mobilized with distal control achieved when feasible. Stent diameter, length and position were determined based on pre-surgical angiograms obtained by cardiac catheterization. Stent diameter was determined by the size of the normal adjacent $\operatorname{vessel}(\sim 1 \mathrm{~mm}$ larger than adjacent or distal PA diameter) and no more than 3 times the diameter of the narrowest stenotic PA segment. Whenever possible, stent length was chosen to avoid jailing side branches of distal vessels. Other than direct visual inspection, no other modality, including fluoroscopy, angiography or other visualization techniques (e.g., endoscopy) were utilized. Stent position was defined as ostial/proximal for stents placed prior to the first PA bifurcation and distal for stents placed after the first PA bifurcation. For stents placed in proximal or ostial locations, the proximal end of the stent was manually widened or "flared" into the main PA, helping to secure the stent in place and facilitating future access into the stent lumen during cardiac catheterization. Only balloon-expandable, bare metal stents were used, and whenever possible, medium and large diameter stents were selected (16).

\section{Statistical Analysis:}


Patient and stent characteristics and short- and long-term patient outcomes are described as frequency with percentage for categorical variables and median with interquartile range (IQR) for continuous variables. Freedom from re-intervention in overall and selected subgroups and overall survival were evaluated by Kaplan-Meier curves. Univariate and multivariable Cox regression analyses were performed to identify factors associated with re-intervention. Variables associated with re-intervention in the univariate analysis $(\mathrm{p}<0.1)$ were incorporated into the multivariable analysis. Due to collinearity between age and body surface area at the time of initial stent implantation, only body surface area was included in the multivariable analysis. Hazard ratio (HR) and 95\% confidence interval from the Cox regression were reported. A p-value $<0.05$ was considered statistically significant. Analyses were performed using SAS Version 9.4 (SAS Institute Inc, Cary, North Carolina).

\section{RESULTS}

\section{Patient Characteristics:}

Eighty-one PA stents were placed in 68 patients (Table I). In the majority of patients (84\%), stent implantation was performed as part of a procedure to repair or palliate another cardiac defect (e.g. conduit replacement). Tetralogy of Fallot (TOF) was the most common diagnosis (38\%) and 11 patients (16\%) had major aortopulmonary collateral arteries (MAPCA), representing $42 \%$ of the patients with TOF.

Intra-operative PA stents were most commonly place in the left PA (59\%) and to treat proximal stenoses (85\%). Medium and large diameter bare metal stents were implanted in 97\% of patients. PALMAZ XL Transhepatic Biliary Stent (58\%. Cordis Endovascular Corporation, Santa Clara, California USA) and ev3 IntraStent ${ }^{\circledR}$ Mega $^{\text {TM }}$ LD Biliary Stent (29\%, ev3 Endovascular, Inc. Plymouth, Minnesota USA) were utilized most frequently.

All patients had previously undergone at least one prior cardiac operation and all patients had undergone at least one prior cardiac catheterization. Twenty-four patients (35\%) had undergone a 
prior PA intervention, either surgical or catheter-based, on the same PA that received an intra-operative PA stent. Of these, 15 patients $(22 \%)$ had undergone at least one prior surgical patch arterioplasty, and 3 patients (4.4\%) had undergone more than 1 arterioplasty. In addition, $12(18 \%)$ had previous transcatheter interventions, 3 of whom (4.4\%) required multiple prior catheter interventions. In these 12 patients, the median time from catheterization to intra-operative stent placement was 91.5 days (IQR 21 days to 2.5 years), whereas the median time from cardiac catheterization (including $\underline{\text { diagnostic and interventional procedures) to intra-operative stent placement was } 22 \text { days (IQR 1-65 }}$ days) for the entire of cohort of patients.

Intra-operative and Hospital Outcomes:

Stent implantation was acutely successful in all patients but one (99\%). This patient developed a distal pulmonary artery laceration requiring immediate stent removal. The procedural complication rate was $4.4 \%(\mathrm{n}=3)$ and all involved a PA injury requiring repair or patch augmentation.

At hospital discharge, 92\% (54/59) of patients had either no or mild residual stenosis by echocardiogram when excluding patients with an unknown degree of residual stenosis (PAs not visualized or echocardiographic images unavailable) (Table II). Of the 9 patients without a sufficient echocardiogram, 6 underwent a cardiac catheterization between 3 days and 20 months after initial stent placement. In these patients, 4 had no stent stenosis and 2 had mild stent stenosis.

\section{Follow-Up Patient Outcomes (Figure 1):}

During a median follow-up period of 6 years (IQR 0.9-12.7), 30 patients (44\%) underwent re-intervention on their intra-operatively placed PA stent(s) (Table III). The median time to first re-intervention was 2.6 years (interquartile range $0.7-4.4$ years). The first re-intervention was a surgical procedure in 9 (30\%) patients, with all undergoing intra-operative dilation of the existing stent, along with a concomitant surgery. No patient required subsequent surgical pulmonary arterioplasty of the stented PA. Only 1

\section{Catheterization and Cardiovascular Interventions}

This article is protected by copyright. All rights reserved. 
patient underwent a surgical procedure for the sole purpose of treating PA stenosis. This patient had single ventricle physiology and because of persistent unilateral lung collapse in the early postoperative period, a lung ventilation perfusion scan was performed which showed no perfusion to unilateral and ipsilateral lung supplied by the stented PA. Therefore, the patient was taken back to the operation room 7 days after the primary surgery with intra-operative stent implantation and underwent surgical thrombectomy and stent dilation with good long term result. Percutaneous intervention was not attempted. The other 8 patients underwent surgery for other indications (conduit revision $[n=4]$, Fontan completion $[n=2]$, Fontan takedown $[n=1]$ and shunt revision $[n=1]$. All 8 patients were able to have the existing stent re-dilated.

The first re-intervention was a percutaneous procedure in $21(70 \%)$ patients, which included balloon angioplasty of the existing stent in 14 and placement of a new stent(s) in 7 . For the 7 patients who had new stents placed, the indication was in-stent stenosis $(n=2)$, somatic growth $(n=3)$, stenosis distal to the intra-operative placed stent $(\mathrm{n}=2)$, and unknown $(\mathrm{n}=1)$.

In the overall cohort, the majority of patients required re-intervention for in-stent stenosis (53\%) and for somatic growth $(30 \%)$. Of note, no patient required re-intervention for either surgical complication or stent fracture at the time of the first re-intervention.

The overall freedom from re-intervention was $83 \%, 74 \%, 51 \%$, and $30 \%$ at $1,2,5$, and 10 years, respectively (Figure 2). The freedom from surgical re-intervention was 95\%, 93\%, 85\%, and 79\% at 1, 2, 5 , and 10 years, respectively.

In univariate cox regression analysis, several factors were associated with an increased risk of reintervention (Table IV). These included age less than 18 months (HR 2.97, p=0.005; Figure 3A) and body surface area less than $0.47 \mathrm{~m}^{2}$ (HR 3.20, $\mathrm{p}=0.003$; Figure $3 \mathrm{~B}$ ) at the time of the initial stent 
implantation, a cardiac diagnosis of TOF (compared to non-TOF patients, HR 2.36, $\mathrm{p}=0.02$; Figure 3C) and the presence MAPCA (HR 3.56, $\mathrm{p}=0.01$ ). On further examination, the increased hazard seen in the TOF group was driven by the presence of MAPCA, as only TOF patients with MAPCA had a significantly higher risk of-re-intervention compared to non-TOF patients (HR 4.61, $\mathrm{p}=0.003$; Figure 3D). There were no differences in the etiology, sidedness, or location of the pulmonary stenosis in terms of risk for re-intervention. Additionally, prior intervention to treat pulmonary stenosis was not associated with re-intervention. Multivariable analysis showed that cardiac diagnosis was independently associated with re-intervention, controlling for body surface area at the time of initial stent implantation and etiology of PA stenosis (Table V).

There were no deaths or long-term complications related to intra-operative stent placement. However, 6 patients died within 30 days of surgery or prior to hospital discharge (whichever was greater) and 8 additional patients died on long-term follow up (median time between surgery and death of 6.0 years [IQR 2.1-13.6 years]). Thus, the actuarial survival was $89 \%, 83 \%, 80 \%$, and $69 \%$ at $1,5,10$, and 15 years (Figure 4). On univariate analysis, there were no factors associated with a higher mortality risk in our patient cohort.

\section{DISCUSSION}

Intra-operative PA stent implantation is an alternative to percutaneous PA stent implantation and surgical pulmonary arterioplasty in many patients. There are several important advantages of intra-operative compared to transcatheter stent implantation, including the ability to implant stents that can be dilated

ultimately to adult-size in small patients, while avoiding injury to peripheral vessels and hemodynamic compromise. In addition, because there is direct access and visualization of the branch pulmonary arteries, the stents can be positioned with flaring of the proximal ends of the stent to facilitate future percutaneous re-dilation or subsequent stent re-implantation. The flaring increases the chance that a wire and catheter enter the stent lumen, rather than through a side-strut. Furthermore, intra-operative PA

\section{Catheterization and Cardiovascular Interventions}


stenting eliminates radiation exposure associated with transcatheter PA stenting. The disadvantages of intra-operative PA stent implantation include the need for a median sternotomy, a high likelihood of patients requiring future stent dilation either due to somatic growth or in-stent stenosis, exposure to cardiopulmonary bypass, and the possibility of jailing side branches of the distal PA.

Importantly, these last two disadvantages may be overcome using a hybrid approach with intraoperative fluoroscopy.

Intra-operative stent placement can be performed successfully in most patients. Of patients who underwent attempted stent placement, a stent was implanted in $99 \%$ of patients. Ninety-two percent of patients had $\leq$ mild residual pulmonary stenosis by echocardiography at hospital discharge and for those patients without an echocardiogram but subsequent PA angiography, $91 \%$ of patients had $\leq$ mild residual stenosis. Unfortunately, not all patients underwent subsequent angiography or additional imaging, like ventilation perfusions scans or cardiac MRI, to better quantitate procedural success. Given the retrospective nature of our study, this data is lacking but will be an important indication in any future prospective studies examining intra-operative PA stenting outcomes.

Additionally, intra-operative PA stent placement can be performed safely. The rates of vascular injury and stent embolization are lower than that reported for percutaneous stent implantation (17). In our series, the total stent related complication rate was $4.4 \%$, whereas the stent-related complication rate was $10 \%$ for percutaneous PA stent placement from a multi-center registry study (17) and $0-40 \%$ reported in a review article summarizing various reports of percutaneous PA stent implantation between 1991 and 2010 (18). Importantly, no patient died during a procedure in which intra-operative stent placement was performed, and there were no deaths as a result of a complication from intra-operative stent placement. Although the 30 -day mortality rate was high at $8.8 \%$, this was related to the high-risk nature of the patients in whom intra-operative stent placement was performed. Three patients underwent intraoperative PA stent placement while already on ECMO support. All underwent successful stent 
implantation but all were unable to wean from ECMO support and died. Two other patients had care withdrawn for severe global hypoxic-ischemic brain injuries after right ventricle to pulmonary artery conduit replacement operations with concomitant intra-operative PA stent implantation. Lastly, one patient underwent a neonatal repair for TOF and absent pulmonary valve, and later underwent intraoperative stent implantation at 3 months of life. The patient died at 1 year of age, 9 months after stent implantation due to complication from ventilator dependence related to severe bronchomalacia.

Eight patients died during long-term follow-up. Seven patients had single ventricle physiology and one had TOF with pulmonary atresia and MAPCA.

In our experience, nearly $44 \%$ of patients require re-intervention of the PA stent during follow-up, and $22 \%$ of patients require more than one re-intervention. Our 2- and 5-year freedom from re-intervention rates of $74 \%$ and $51 \%$ were nearly identical to those found in the one other study examining the longterm outcomes following intraoperative PA stent placement, in which the 2 and 5 year rates were $68 \%$ and $49 \%$, respectively (15). This is in close approximation with reports of percutaneous PA stent placement, where re-intervention rates for stent dilation range from $26-66 \%$ during follow-up periods ranging from 0.9 to 7.2 years (18).

Re-interventions are expected whenever stents are placed in children given anticipated somatic growth. In our study, $30 \%$ of re-interventions were performed for somatic growth. To support this further, two of the main risk factors for re-intervention were age less than 18 months and body surface area less than 0.47 $\mathrm{m}^{2}$ at initial implant.

A cardiac diagnosis of TOF with MAPCA is the other main risk factor for re-intervention. This is not an unexpected finding, as the PAs in patients with MAPCA are often hypoplastic and require multiple interventions, especially during the first several years of life, compared to TOF patients without MAPCA 
$(19,20)$. Furthermore, patients with MAPCA are at a higher risk of developing in-stent stenosis secondary to neointimal proliferation (21). These patients need close monitoring, and frequent reintervention should be expected.

Fortunately, the majority of patients who require re-intervention after placement of an intra-operative PA stent can undergo re-intervention via percutaneous techniques. We believe that this is facilitated by placing stents that can be serially balloon dilated to adult sizes and to flaring the proximal edge of the stent.

In this study, stents were placed on $\mathrm{CPB}$ by direct visualization alone, using pre-surgical angiography to determine stent sizes. The disadvantages to this approach include exposure to CPB and the inability to visualize, avoid, and/or treat side vessel jailing or vessel wall injury during stent implantation. In our cohort, the median CPB duration was 50 minutes (IQR 38-90 minutes) for patients undergoing isolated intra-operative PA stenting. Although difficult to determine CPB duration related to stent implantation when performed during additional cardiac procedures requiring CPB, anecdotally, most stents can be prepared and implanted in less than 15 minutes. There are alternative methods for placing intra-operative PA stents, such as hybrid-implantation, using intra-operative angiography and fluoroscopy. This is particularly useful for placing stents distally or at PA bifurcations. This helps to avoid jailing side branches and facilitates opening the side struts into side branches, if needed. Additionally, hybrid stent implantation can be done without using CPB, thereby eliminating the deleterious effects of bypass in patients not undergoing concomitant procedures. This does, however, expose patients to ionizing radiation. Thus, the risks and benefits of each modality should be considered on an individual basis.

Our current practice is to utilize intra-operative PA stent placement in patients with significant PA stenosis that is not amenable to balloon angioplasty or surgical patch arterioplasty (because of the nature 
of the lesion and/or poor response to prior angioplasty or arterioplasty) and who are undergoing a concomitant surgical procedure. Additionally, intra-operative PA stent placement is performed in patients in whom a transcatheter approach is not feasible, either due to the size of the peripheral vasculature or due to hemodynamic instability during attempted stent implantation. Importantly, there have been many advances in pre-mounted stent technology in the last 5 years, allowing implantation using much smaller sheath sizes than are needed for unmounted large bare metal stents. Therefore the ultimate desired size of the stent needs to be taken into account when deciding on the appropriate therapy for a patient.

\section{Limitations:}

Due to the retrospective nature of this study, it was not possible to re-create the decision-making that went into performing surgical arterioplasty versus surgical or percutaneous stent implantation. We can make some inferences, however the exact indication for intra-operative stent implantation was sometimes unknown, and, thus, selection bias could impact our results. Likewise, stent choice and size, as well as the indications for re-intervention are difficult to delineate retrospectively.

\section{CONCLUSION}

Intra-operative PA stent implantation is technically feasible with low procedural, stent-related complications. The rates of central vascular injury and stent embolization are lower than that reported for percutaneous stent implantation (17) and radiation exposure is eliminated. Similar to what is reported with percutaneous stent implantation, re-intervention is common. When utilized in younger patients and patients with MAPCA, re-intervention for either development of in-stent stenosis and/or somatic growth should be expected. This study expands the knowledge of intra-operative PA stent placement and the impact of stents placed largely during childhood on late outcomes.

Acknowledgements and Disclosures: None 

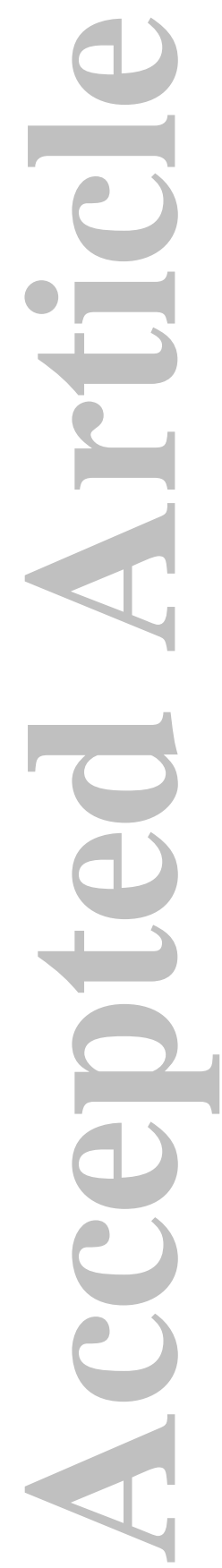

Catheterization and Cardiovascular Interventions

This article is protected by copyright. All rights reserved. 


\section{References}

1. Bacha EA, Kreutzer J. Comprehensive management of branch pulmonary artery stenosis. Journal of interventional cardiology 2001;14(3):367-375.

2. Patel ND, Kenny D, Gonzalez I, Amin Z, Ilbawi MN, Hijazi ZM. Single-center outcome analysis comparing reintervention rates of surgical arterioplasty with stenting for branch pulmonary artery stenosis in a pediatric population. Pediatric cardiology 2013.

3. Trant CA, Jr., O'Laughlin MP, Ungerleider RM, Garson A, Jr. Cost-effectiveness analysis of stents, balloon angioplasty, and surgery for the treatment of branch pulmonary artery stenosis. Pediatric cardiology 1997;18(5):339-344.

4. McGoon DC, Kincaid OW. Stenosis of branches of the pulmonary artery: Surgical repair. The Medical clinics of North America 1964;48:1083-1088.

5. Vida VL, Rito ML, Zucchetta F, Biffanti R, Padalino MA, Milanesi O, Stellin G. Pulmonary artery branch stenosis in patients with congenital heart disease. Journal of cardiac surgery 2013;28(4):439-445.

6. Bokenkamp R, Blom NA, De Wolf D, Francois K, Ottenkamp J, Hazekamp MG. Intraoperative stenting of pulmonary arteries. European journal of cardio-thoracic surgery : official journal of the European Association for Cardio-thoracic Surgery 2005;27(4):544-547.

7. Coles JG, Yemets I, Najm HK, Lukanich JM, Perron J, Wilson GJ, Rabinovitch M, Nykanen DG, Benson LN, Rebeyka IM, Trusler GA, Freedom RM, Williams WG. Experience with repair of congenital heart defects using adjunctive endovascular devices. The Journal of thoracic and cardiovascular surgery 1995;110(5):1513-1519; discussion 1519-1520.

8. Holzer RJ, Chisolm JL, Hill SL, Olshove V, Phillips A, Cheatham JP, Galantowicz M . "Hybrid" stent delivery in the pulmonary circulation. The Journal of invasive cardiology 2008;20(11):592-598.

9. Menon SC, Cetta F, Dearani JA, Burkhart HA, Cabalka AK, Hagler DJ. Hybrid intraoperative pulmonary artery stent placement for congenital heart disease. The American journal of cardiology 2008;102(12):1737-1741. 
10. Mitropoulos FA, Laks H, Kapadia N, Gurvitz M, Levi D, Williams R, Plunkett M. Intraoperative pulmonary artery stenting: An alternative technique for the management of pulmonary artery stenosis. The Annals of thoracic surgery 2007;84(4):1338-1341; discussion 1342.

11. Ungerleider RM, Johnston TA, O'Laughlin MP, Jaggers JJ, Gaskin PR. Intraoperative stents to rehabilitate severely stenotic pulmonary vessels. The Annals of thoracic surgery 2001;71(2):476-481. 12. Mendelsohn AM, Bove EL, Lupinetti FM, Crowley DC, Lloyd TR, Fedderly RT, Beekman RH. Intraoperative and percutaneous stenting of congenital pulmonary artery and vein stenosis. Circulation 1993;88(5 Pt 2):II210-217.

13. Lynch W, Boekholdt SM, Hazekamp MG, de Winter RJ, Koolbergen DR. Hybrid branch pulmonary artery stent placement in adults with congenital heart disease. Interactive cardiovascular and thoracic surgery 2015;20(4):499-503.

14. Sridhar A, Subramanyan R, Premsekar R, Chidambaram S, Agarwal R, Manohar SRK, Cherian KM. Hybrid intraoperative pulmonary artery stenting in redo congenital cardiac surgeries. Indian heart journal 2014;66(1):45-51.

15. Angtuaco MJ, Sachdeva R, Jaquiss RD, Morrow WR, Gossett JM, Fontenot E, Seib PM. Longterm outcomes of intraoperative pulmonary artery stent placement for congenital heart disease. Catheter Cardiovasc Interv 2011;77(3):395-399.

16. Peters B, Ewert P, Berger F. The role of stents in the treatment of congenital heart disease:

Current status and future perspectives. Annals of pediatric cardiology 2009;2(1):3-23.

17. Holzer RJ, Gauvreau K, Kreutzer J, Leahy R, Murphy J, Lock JE, Cheatham JP, Bergersen L. Balloon angioplasty and stenting of branch pulmonary arteries: Adverse events and procedural characteristics: Results of a multi-institutional registry. Circ Cardiovasc Interv 2011;4(3):287-296.

18. Krisnanda C, Menahem S, Lane GK. Intravascular stent implantation for the management of pulmonary artery stenosis. Heart, lung \& circulation 2013;22(1):56-70.

19. Carotti A, Albanese SB, Flipelli S, Rava L, Guccione P, Pongiglione G, Di Donato RM . Determinants of outcome after surgical treatment of pulmonary atresia with ventricular septal defect and 
major aortipulmonary collateral arteries. The Journal of thoracic and cardiovascular surgery 2010;140(5):1092-1103.

20. Amark KM, Karamlou T, O’Carroll A, MacDonald C, Freedom RM, Yoo SH, Williams WG, Van Arsdell GS, Caldaerone CA, McCrindle BW. Independent factors associated with mortality, reintervention, and achievement of complete repair in children with pulmonary atresia with ventricular septal defect. JACC 2006;47(7):1149-1156.

21. Hallbergson A, Lock JE, Marshall AC. Frequency and risk of in-stent stenosis following pulmonary artery stenting. Am J Cardiol 2014;113(3):541-545.

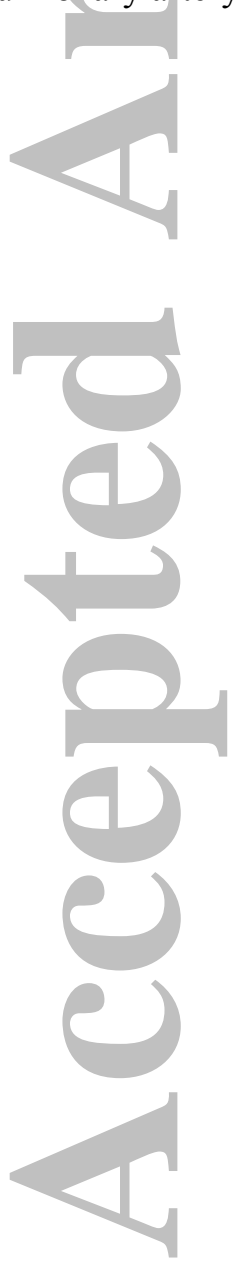




\section{Figure Legends:}

1: Patient outcomes flow chart

2: Freedom from first re-intervention in the overall cohort stratified by the type of re-intervention (surgical versus percutaneous). The median time to re-intervention is 5.3 years for the overall cohort, as illustrated by the dotted line. The $(*)$ indicates that no patient in any cohort was at risk after 10 years, and therefore, the figure was truncated to only include the first 10 years of follow-up.

3: Freedom from first re-intervention stratified by various clinical characteristics, including age (3A), body surface area (3B), cardiac diagnosis (3C), and cardiac diagnosis with presence of MAPCAs (3D). Median freedom from re-intervention is represented for each group by the dotted lines.

Abbreviations: BSA, body surface area; MAPCA, multiple aorto-pulmonary collateral arteries; non-TOF, diagnosis other than tetralogy of Fallot; TOF, tetralogy of Fallot.

4: Overall survival of the entire cohort $(n=68)$

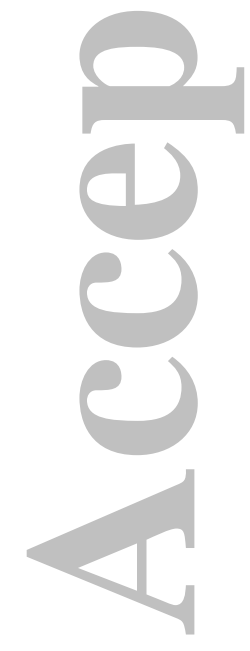

